\title{
Doxorubicin-DNA Complex
}

National Cancer Institute

\section{Source}

National Cancer Institute. Doxorubicin-DNA Complex. NCI Thesaurus. Code C1075.

A complex comprised of Doxorubicin linked to DNA to enhance the topoisomerase IImediated interaction with the DNA base pairs and reduce cardiotoxicity associated with anthracyclines. $(\mathrm{NCl})$ 